\title{
Temperature Effects on the Mechanical Properties of Candidate SNS Target Container Materials after Proton and Neutron Irradiation
}

\author{
T.S. Byun, K. Farrell, E.H. Lee, L.K. Mansur \\ S.A. Maloy, M.R. James, and W.R. Johnson
}

September 2001

Oak Ridge National Laboratory 


\title{
Temperature Effects on the Mechanical Properties of Candidate SNS Target Container Materials after Proton and Neutron Irradiation
}

\author{
T.S. Byun, K. Farrell, E.H. Lee, L.K. Mansur \\ Oak Ridge National Laboratory, P.O. Box 2008, Oak Ridge, TN 37831 \\ S.A. Maloy, M.R. James \\ Los Alamos National Laboratory, MS H809, Los Alamos, NM 87545 \\ W.R. Johnson \\ General Atomics, PO Box 85608, San Diego, CA 92186
}

September 2001

Prepared for the

U.S. Department of Energy

Office of Science

UT-BATTELLE, LLC

managing

Spallation Neutron Source Activities at

Argonne National Laboratory

Brookhaven National Laboratory

Thomas Jefferson National Accelerator Facility

Lawrence Berkeley National Laboratory

Los Alamos National Laboratory

Oak Ridge National Laboratory

under contract DE-AC05-00OR22725

for the

U.S. DEPARTMENT OF ENERGY 


\title{
Temperature Effects on the Mechanical Properties of Candidate SNS Target Container Materials after Proton and Neutron Irradiation*
}

\author{
T.S. Byun ${ }^{1}$, K. Farrell ${ }^{1}$, E.H. Lee ${ }^{1, \dagger}$, L.K. Mansur ${ }^{1}$, \\ S.A. Maloy ${ }^{2}$, M.R. James ${ }^{2}$, and W.R. Johnson ${ }^{3}$
}

\begin{abstract}
This report presents the tensile properties of EC316LN austenitic stainless steel and 9Cr-2WVTa ferritic/martensitic steel after $800 \mathrm{MeV}$ proton and spallation neutron irradiation to doses in the range 0.54 to $2.53 \mathrm{dpa}$. Irradiation temperatures were in the range 30 to $100^{\circ} \mathrm{C}$. Tensile testing was performed at room temperature $\left(20^{\circ} \mathrm{C}\right)$ and $164^{\circ} \mathrm{C}$ to study the effects of test temperature on the tensile properties. Test materials displayed significant radiation-induced hardening and loss of ductility due to irradiation. The EC316LN stainless steel maintained notable strain-hardening capability after irradiation, while the $9 \mathrm{Cr}-2 \mathrm{WVTa}$ ferritic/martensitic steel posted negative strain hardening. In the EC316LN stainless steel, increasing the test temperature from $20^{\circ} \mathrm{C}$ to $164^{\circ} \mathrm{C}$ decreased the strength by 13 to $18 \%$ and the ductility by 8 to $36 \%$. The tensile data for the EC316LN stainless steel irradiated in spallation conditions were in line with the values in a database for 316 stainless steels for doses up to $1 \mathrm{dpa}$ irradiated in fission reactors at temperatures below $200^{\circ} \mathrm{C}$. However, extra strengthening induced by helium and hydrogen contents is evident in some specimens irradiated to above about $1 \mathrm{dpa}$. The effect of test temperature for the 9Cr-2WVTa ferritic/martensitic steel was less significant than for the EC316LN stainless steel.

In addition, strain-hardening behaviors were analyzed for EC316LN and 316L stainless steels. The strain-hardening rate of the 316 stainless steels was largely dependent on test temperature. It was estimated that the 316 stainless steels would retain more than $1 \%$ true stains to necking at $164{ }^{\circ} \mathrm{C}$ after irradiation to $5 \mathrm{dpa}$. A calculation using reduction of area (RA) measurements and stress-strain data predicted positive strain hardening during plastic instability.
\end{abstract}

\footnotetext{
${ }^{1}$ Oak Ridge National Laboratory, P.O. Box 2008, Oak Ridge, TN 37831

${ }^{\dagger}$ Presently Honeywell Electronics Materials, 1349 Moffett Park Dr., Sunnyvale, CA 94089

${ }^{2}$ Los Alamos National Laboratory, MS H809, Los Alamos, NM 87545

${ }^{3}$ General Atomics, PO Box 85608, San Diego, CA 92186
} 


\section{Introduction}

The container vessel for the mercury target of the proposed SNS is expected to operate at a temperature between $100^{\circ} \mathrm{C}$ and $200^{\circ} \mathrm{C}$ [1]. A goal exposure for the first target is six months operation, corresponding to a displacement dose of about $5 \mathrm{dpa}$ in the container vessel. In earlier reports [2-7] we described the tensile properties of candidate vessel materials after irradiation in the Los Alamos Neutron Scattering Center (LANSCE) accelerator at Los Alamos National Laboratory (LANL) at temperatures in the range $58-160^{\circ} \mathrm{C}$. The tensile tests were conducted at ORNL at room temperature. Austenitic stainless steels showed the most satisfactory results. They retained significant ductility even after irradiation to $11 \mathrm{dpa}$; the EC316LN steel had positive work hardening and a uniform elongation of $6 \%[2,5]$. Ferritic/martensitic steels displayed prompt instability failures at yield.

In the same LANSCE experiment, other materials were irradiated and tested by LANL for consideration for use in their Accelerator Production of Tritium (APT) project [11-13]. Two stainless steels, $316 \mathrm{~L}$ and $304 \mathrm{~L}$, were tested at 50,80 , and $164^{\circ} \mathrm{C}$, and they showed greater ductility losses than for ORNL's austenitic steels [6,7]. In LANL's engineering stress-strain data, all stainless steel specimens that were irradiated to doses higher than 2 dpa and tested at 80 or $164^{\circ} \mathrm{C}$ showed nearly zero or negative strain hardening, and almost no uniform elongation. Comparison with the ORNL data suggested that test temperature was obviously an important factor in reduced ductility [6-10], but the role of chemical composition of the steels was unclear. Subsequent tests at LANL [6] established that test temperature overrules effects of chemical composition in the LANL austenitic steels.

To confirm the temperature effects on tensile properties for the SNS candidate materials, a few available specimens of the irradiated EC316LN austenitic steel and a 9Cr-2WVTa ferritic/martensitic steel were performed at room temperature and $164^{\circ} \mathrm{C}$. The latter temperature was chosen to conform to LANL's highest test temperature. This report presents the tensile test results, focusing on the effects of test temperature on tensile properties. In addition, detailed analyses on strain-hardening behaviors are performed for the uniform and localized deformation regimes of ORNL's EC316LN and LANL's 316L stainless steels. No detailed analysis was performed for the strain hardening behaviors of the ferritic/martensitic steel because it showed prompt plastic instability after irradiation.

\section{Experiments and analyses}

Test materials were EC316LN austenitic stainless steel and 9Cr-2WVTa ferritic/martensitic steel. Table 1 lists their identities, chemical compositions, and heat treatments. SS-3 type tensile samples were irradiated and tested. The SS-3 tensile specimen is shown in Fig. 1. Its nominal gage section dimensions are $7.6 \mathrm{~mm}$ long, $1.5 \mathrm{~mm}$ wide, and $0.76 \mathrm{~mm}$ thick.

For the present tensile testing, eight SS-3 tensile specimens were irradiated at two different positions in Tube 4 of Insert 17A, an in-beam position of the LANSCE-APT irradiation setup [11-13]. In the irradiation experiment, specimens were irradiated with a beam of $800 \mathrm{MeV}$ protons at an average current of $1 \mathrm{~mA}$ and with spallation neutrons $[14,15]$ emitted from a 
tungsten target. The exposure for each specimen was dependent on its radial and axial position relative to the beam center and the tungsten target. The doses evaluated were 0.54 and $1.87 \mathrm{dpa}$ for EC316LN steel specimens and 0.52 and 2.53 dpa for 9Cr-2WVTa steel specimens. He and $\mathrm{H}$ productions were in the range of 40 to $200 \mathrm{appm}$ and 200 to 1600 appm, respectively. Irradiation temperatures were in the range 30 to $100^{\circ} \mathrm{C}$. These irradiation conditions are summarized in Table 2, and additional information on the LANSCE-APT experiment is given in previous reports $[11,13]$.

Tensile testing was performed at room temperature $\left(20^{\circ} \mathrm{C}\right)$ and an elevated temperature $\left(164{ }^{\circ} \mathrm{C}\right)$ in a screw-driven machine at a crosshead speed of $0.008 \mathrm{~mm} / \mathrm{sec}$, corresponding to a nominal strain rate of $10^{-3} \mathrm{sec}^{-1}$. An unirradiated gauge length of $7.6 \mathrm{~mm}$ was taken as the reference gage length for calculation of engineering and true strains. Engineering stresses were calculated as the load divided by initial cross-sectional area measured before irradiation. True stress $(\sigma)$-true strain $(\varepsilon)$ data and strain hardening rate $(\mathrm{d} \sigma / \mathrm{d} \varepsilon)$ were calculated from the engineering stress-strain data and used to determine true uniform strains, or true strains to plastic instability. Strain hardening analysis was also performed on the earlier tensile test data of LANL's 316L stainless steel [6,7] to compare with the new results for EC316LN stainless steel. Strain-hardening rates for necking deformation were predicted from measurements of reduction of area (RA) and tensile test data for the 316L stainless steel [16]. The RA data were measured on the fracture surface using a Scanning Electron Microscope.

\section{Results and discussion}

\subsection{EC316LN austenitic stainless steel}

Fig. 2 presents engineering stress-strain curves for EC316LN stainless steel. The engineering tensile data read from the curves are summarized in Table 3. The EC316LN stainless steel showed considerable radiation hardening and loss of ductility after irradiation. At both $20{ }^{\circ} \mathrm{C}$ and $164{ }^{\circ} \mathrm{C}$ the yield strengths at $1.87 \mathrm{dpa}$ were three times higher than those for the unirradiated condition, and the uniform strain was reduced to about one fourth of its unirradiated value. Despite the loss in ductility the EC316LN stainless steel retained positive strain hardening after irradiation up to $1.87 \mathrm{dpa}$ at both temperatures.

As expected, the EC316LN stainless steel showed significant temperature effects on tensile properties [6,7]. With increasing test temperature from 20 to $164^{\circ} \mathrm{C}$, the yield and ultimate tensile strengths (YS and UTS) decreased by 13 to $18 \%$ from their room temperature values. These percentage reductions in strengths seemed to be insensitive to irradiation dose between 0.5 to $1.9 \mathrm{dpa}$. The increase of test temperature also reduced the ductility of EC316LN stainless steel. The reduction in ductility was most pronounced in the unirradiated condition; Table 3 shows $26 \%$ reduction in uniform elongation (UE) and $24 \%$ reduction in total elongation (TE). After irradiation to $1.87 \mathrm{dpa}$ the percentage reductions in ductility due solely to the increase of temperature were about $8 \%$ and $12 \%$ for uniform and total elongations, respectively.

In Figs. 3 and 4 the tensile data for current EC316LN specimens are overlaid on the trend bands of the database for 316 stainless steels irradiated at temperatures between room temperature and 
$200^{\circ} \mathrm{C}$ in fission reactors and tested in the same temperature range [17]. Further, the data are compared with the previous room temperature data for candidate SNS target container materials irradiated in neutron (n) or proton ( $\mathrm{p}$ ) areas of the LANSCE-APT irradiation [2-5]. At doses below about 1 dpa both yield strength and uniform elongation data for LANSCE irradiations are compatible with the trend bands of the database. At higher doses, however, the yield strengths of the LANSCE specimens tend to exceed the upper bound of the fission reactor data, and the uniform elongation becomes close to the lower bound of the database. This extra strengthening is attributable to the higher helium and hydrogen contents generated by spallation reactions. Using nanoindentation technique, room temperature hardness data have been obtained for $316 \mathrm{LN}$ stainless steel specimens after irradiation with iron, helium, and hydrogen ions at $200^{\circ} \mathrm{C}$ [18]. The data indicated that the additional hardening effect from helium (hydrogen) bubbles became significant at helium concentrations above 1 at.\%. In the spallation condition, the helium concentration at the highest dose of $11 \mathrm{dpa}$ was about 0.1 at.\% [3-5]. Thus, some strengthening contribution due to the presence of the gases is expected at the highest dose. This extra strengthening from the gases is noticeable in room temperature tests but is expected to extend to more elevated test temperatures. The temperature effects noted herein for the yield strength of EC316LN steel are nearly independent of dose in the range $0-1.87 \mathrm{dpa}$. This trend might persist to higher doses.

\subsection{Cr-2WVTa ferritic/martensitic steel}

Engineering stress-strain curves for 9Cr-2WVTa ferritic/martensitic steel are displayed in Fig. 5, and the engineering tensile data are listed in Table 3. Irradiation hardening in the ferritic/martensitic steel was strong but less than in the austenitic stainless steel; the yield strengths at $2.53 \mathrm{dpa}$ were less than two times those for unirradiated specimens. All the irradiated specimens displayed plastic instability at yield. This was anticipated from previous tensile data for low doses, which found that at room temperature the critical dose to prompt plastic instability at yield is about $0.1 \mathrm{dpa}$ for the alloy [4]. Consequently, the uniform elongations are near zero and the ultimate tensile strengths equal the yield strengths [19-21].

The effects of test temperature on the tensile properties are weaker in the 9Cr-2WVTa steel than in the EC316LN stainless steel. The ferritic/martensitic steel saw about $10 \%$ reduction in the yield strength by increasing test temperature from 20 to $164^{\circ} \mathrm{C}$. The increase of test temperature caused about $20 \%$ reduction in uniform elongation before irradiation but little difference in ductility after irradiation.

\subsection{Strain-hardening behavior in austenitic stainless steels}

Figs. 6 to 8 present true stress $(\sigma)$-true strain $(\varepsilon)$ curves and strain-hardening rate $(\mathrm{d} \sigma / \mathrm{d} \varepsilon)$ curves for EC316LN stainless steel. In the unirradiated EC316LN stainless steel no yield drop was discerned and the true stress increased steadily with increasing true strain. Very high strainhardening rates were calculated for the initial small plastic strains because the unirradiated steel showed a continuous yielding, a smooth transition from a high-modulus elastic deformation to 
plastic deformation without an apparent yield point. The strain-hardening rate decreased with increasing strain but was above the true stress-true strain curve until plastic instability occurred.

It is assumed that the plastic instability or necking initiates at the intersection of the $\sigma$ versus $\varepsilon$ curve and the $\mathrm{d} \sigma / \mathrm{d} \varepsilon$ versus $\varepsilon$ curve [22]; i.e., Considere's criterion is applied to obtain the true strain to plastic instability:

$\sigma=\frac{d \sigma}{d \varepsilon}$

Fig. 6 shows that the true plastic strains at the intersections are about 0.49 and 0.39 for the unirradiated specimens tested at 20 and $164^{\circ} \mathrm{C}$, respectively. Note that the values for true stress and strain-hardening rate become invalid after the onset of plastic instability because of invalidity of true strain values.

As illustrated in Figs. 7 and 8, irradiation changed the shapes of true stress-true strain and strainhardening rate versus strain curves at low strains. At both test temperatures the irradiated stainless steel showed small yield drops within a narrow strain range, in which strain-hardening rates were negative. These early low strain portions of the strain-hardening rate versus strain curves corresponding to elastic deformation and yield drop are omitted in Figs. 7 and 8. After the yield drops, however, the strain hardening rate recovered quickly to positive value and followed similar curve shapes to those of the unirradiated specimens, although strain-hardening rate was lowered with increasing dose. In Figs. 7 and 8 several intersections exist between true stress-true strain curve and strain-hardening rate curve; at least, one on recovery from negative hardening due to the yield drop and another at the onset of plastic instability. To determine a point at which plastic instability was initiated, the last intersection was assumed to be responsible for the real necking. At doses of 0.54 and $1.87 \mathrm{dpa}$ the true strains to plastic instability were in the range 0.11 to 0.25 .

Large temperature effects were observed on both irradiation-induced strengthening and strainhardening rate. A $140^{\circ} \mathrm{C}$ increase in test temperature lowered the true-stress levels by 10 to $20 \%$ and reduced the strain-hardening rate more significantly, resulting in reductions of uniform strain and instability stress. However, all EC316LN stainless steel specimens irradiated to 0.54 or 1.87 dpa retained positive strain-hardening rate.

At room temperature, the EC316LN stainless steel retained a strong positive strain-hardening capability in the dose range of 0 to $11 \mathrm{dpa}$ [2-5]. An analysis of the dose dependence of yield stress, instability stress, and fracture stress [5] indicated that the dose to plastic instability at yield would have been about 18 dpa for the EC316LN stainless steel at room temperature. However, the LANL results on 316L stainless steel [6,7], irradiated in the same LANSCE-APT experiment with the present EC316LN stainless steel, showed that the steel experienced a prompt necking at yield at $164^{\circ} \mathrm{C}$ after irradiation to $8.7 \mathrm{dpa}$. At $164^{\circ} \mathrm{C}$, therefore, the dose to a prompt plastic instability at yield must have been equal to or less than $8.7 \mathrm{dpa}$. In the present work we predicted true strains to plastic instability for both EC316LN and 316L alloys by analyzing existing tensile curves $[2-5,6]$ and gave the values for uniform true strain at $5 \mathrm{dpa}$. This is the recommended dose at which the first SNS target modules will be removed from service. 
Considere's criterion [22], $\sigma=\mathrm{d} \sigma / \mathrm{d} \varepsilon$, was applied to determine the true strain to plastic instability, or true strain to necking, rather than reading the uniform elongation at the ultimate tensile strength point. This is because the true strain to plastic instability can be clearly defined on the true stress-true strain and strain hardening curves by applying Considere's criterion, while the uniform elongation is not easily determined when the engineering stress-strain curve is nearly flat during uniform deformation. In some irradiated specimens the ultimate tensile strength may be coincident with the yield strength although the material shows positive strain hardening in the true stress unit after a yield drop [3,6]. If the yield drop is large but the strain hardening after the yield drop is very modestly positive, the strength after yield can not reach the yield strength level until the specimen starts necking. This is because the reduction of cross-sectional area due to uniform deformation offsets positive strain hardening, producing an almost flat engineering stress-strain curve before necking occurs. This type of behavior was observed in the LANL 316 steel tested at $164^{\circ} \mathrm{C}$ and shown in Figs. 9 and 10. Applying Considere's criterion, values of 0.018 and 0.033 were determined for true strains to plastic instability at doses of 2.9 and 4.1 dpa, respectively. As explained above, the engineering stress-strain curves in Figs. 9 and 10 are almost flat in the true uniform strain range.

True plastic strain to plastic instability was evaluated for all EC316LN and 316L stainless steel specimens that exhibited uniform deformation. Existing room temperature data for EC316LN steel [5] and new data for EC316LN and 316L steels are regrouped into three data sets with respect to test temperatures: 20,50 , and $164^{\circ} \mathrm{C}$, as listed in Table 4 , and used for producing regression curves for the test temperatures. Fig. 11 shows the variation of true strains to plastic instability with dose for each temperature. Trend lines were obtained in the forms of exponential functions, which gave good regression results for the ductility versus dose data, and were used for interpolations. Comparing the curves indicates that test temperature has a large effect on the dose dependence of true strain to plastic instability in austenitic stainless steels. Reduction in ductility due to irradiation was more significant at 50 and $164^{\circ} \mathrm{C}$ than at $20^{\circ} \mathrm{C}$. Interpolations to 5 dpa gave about $0.163,0.042$ and 0.018 for true strains to plastic instability at 20,50 and $164^{\circ} \mathrm{C}$, respectively. These results predict that the 316 stainless steels will not experience a prompt necking at yield at temperatures of $164^{\circ} \mathrm{C}$ or below until the dose reaches higher than $5 \mathrm{dpa}$, as shown in Figure 11.

Table 4 and Figure 11 also show that for unirradiated stainless steels uniform elongation is strongly affected by test temperature. This is confirmed by ongoing experiments at ORNL on unirradiated $316 \mathrm{LN}$ and $304 \mathrm{~L}$ stainless steels, which display large $(\sim 40 \%)$ reductions in uniform elongation when the test temperature is raised from $0^{\circ} \mathrm{C}$ to $200^{\circ} \mathrm{C}$ [23].

\subsection{Strain-hardening rate during necking}

When the $316 \mathrm{~L}$ stainless steel was tested at $164^{\circ} \mathrm{C}$ after irradiation to above 8 dpa, deformation was localized from the beginning stage of plastic deformation [6,7]. This prompt plastic instability resulted in very small uniform strains of less than $0.5 \%$, consistent with Fig. 11 . There has been a question about the strain-hardening behavior after the plastic instability at yield $[22,24,25]$. Since it is impossible to calculate true strain and true stress data at the neck without its cross-sectional area data, the dimensional change of the neck should be measured to investigate the strain-hardening behavior over the necking process. Van Osch and de Vries [24] 
have measured the reduction of area and calculated true stress and true strain for a $\mathrm{V}-4 \mathrm{Cr}-4 \mathrm{Ti}$ alloy. In this result, the specimen neutron-irradiated to about $6 \mathrm{dpa}$ and tested at $327^{\circ} \mathrm{C}$ displayed prompt necking at yield, however, both the irradiated and unirradiated specimens showed similar positive strain-hardening rates after the onset of necking [24].

Reduction of area (RA), as a percentage change from original area to final cross-sectional area after fracture, has been measured for selected specimens, including three 316L stainless steel specimens [16]. Photographs of fracture surfaces were obtained by scanning electron microscopy to measure the final cross-sectional areas. The RA values for 316L stainless steel were in the range $63-73 \%$. Using those RA measurements and tensile test data, we have attempted to calculate the strain-hardening rate during necking. For simplicity, linear hardening is assumed for the true stress-true strain curve of the necking deformation [24,25]:

$\sigma=\sigma_{u}+h_{n}\left(\varepsilon-\varepsilon_{u}\right)$

where

$\sigma_{u}=$ instability stress

$h_{n}=$ strain-hardening rate during necking

$\varepsilon_{u}=$ true strain to plastic instability (true uniform strain)

We can also read fracture strength, $S_{f}$, from the engineering stress-strain curve. Then the true fracture strain, $\varepsilon_{f}$, and true fracture stress, $\sigma_{f}$, can be calculated by

$$
\begin{aligned}
& \varepsilon_{f}=\ln \left(\frac{1}{1-R A / 100}\right) \\
& \sigma_{f}=S_{f} e^{\varepsilon_{f}}
\end{aligned}
$$

Using these parameters, $h_{n}$ is expressed by

$$
h_{n}=\frac{S_{f} e^{\varepsilon_{f}}-\sigma_{u}}{\varepsilon_{f}-\varepsilon_{u}}
$$

Strain-hardening rates during plastic instability deformation for three 316L specimens are listed in Table 5, along with results for other parameters. Indeed, our result on strain-hardening behavior agrees with van Osch and de Vries' result on V-4Cr-4Ti alloy [16]; all calculated values for strain-hardening rate are decisively positive. Table 5 also shows that the average strain-hardening rate for necking deformation, $h_{n}$, is similar to the strain-hardening rate at onset of necking $\left(=\sigma_{u}\right)$. It is interesting to note that the $h_{n}$ value for the specimen irradiated to $9.2 \mathrm{dpa}$, which showed prompt necking at yield, can retain a high strain-hardening rate of about $800 \mathrm{MPa}$ during plastic instability. 
The result of the high strain-hardening rates for necking deformation is seemingly contrary to the fact that, as indicated in Figs. 6 to 10, the strain-hardening rate decreases rapidly over the uniform strain range. Assuming that the strain-hardening rate continues to decrease during necking at the same rate, it will become a small positive value or most likely a negative value at fracture strains as high as those in Table 5. However, two complicating factors need to be considered. First, a multi-axial stress state is developed by the geometry of the necked region [24-26]. Since we calculate the true stress values for the neck by dividing applied load by crosssectional area, the calculated true stress is not the equivalent stress that describes uniaxial uniform deformation but is the axial stress component in the loading direction. It has been shown that this axial stress component can be much higher than the equivalent stress at a given strain $[22,25,26]$, depending on specimen geometry. Second, the complexities of geometry and stress state in the necked region would activate additional dislocation slip systems or even different deformation mechanisms of the material. This can help to sustain a high strain-hardening rate, which usually falls during uniform deformation. Although the current data on strain-hardening rate should be revised in terms of equivalent stress, it is encouraging that the austenitic stainless steels are expected to retain positive hardening during instability deformation after irradiation to at least 9 dpa.

\section{Summary and conclusions}

Temperature effects on the tensile properties of EC316LN austenitic stainless steel and 9Cr2 WVTa ferritic/martensitic steel were investigated after proton and neutron irradiation to doses up to $2.53 \mathrm{dpa}$. Tensile testing was performed at two temperatures, 20 and $164^{\circ} \mathrm{C}$. Further, the strain-hardening behavior was analyzed for EC316LN and 316L alloys to study temperature effects and to obtain true strains to plastic instability. The results of the testing and analysis are summarized as follows:

(1) All test materials showed significant radiation-induced hardening and loss of ductility due to irradiation. In the engineering stress-strain curves the EC316LN stainless steel maintained notable strain-hardening capability while the $9 \mathrm{Cr}-2 \mathrm{WVTa}$ ferritic/martensitic steel posted negative hardening.

(2) In the EC316LN stainless steel, increasing the test temperature from $20^{\circ} \mathrm{C}$ to $164^{\circ} \mathrm{C}$ decreased the strength by 13 to $18 \%$ and reduced the ductility by 8 to $36 \%$. The effect of test temperature in the $9 \mathrm{Cr}-2 \mathrm{WVTa}$ ferritic/martensitic steel was less significant than in the EC316LN stainless steel.

(3) At doses less than about 1 dpa the tensile data of the LANSCE-irradiated stainless steels were in line with the fission reactor database for 316 stainless steels irradiated and tested at temperatures below $200^{\circ} \mathrm{C}$. However, extra strengthening induced by helium and hydrogen contents is evident in some specimens irradiated to above about 1 dpa.

(4) The plastic instability analysis results indicated that modest increase in tensile test temperature has large effects on the dose dependence of true strain to plastic instability in austenitic stainless steels. Interpolations with true uniform strain versus dpa data showed that 
the 316 stainless steels would retain more than $1 \%$ uniform strain after irradiation to 5 dpa for test temperature up to $164^{\circ} \mathrm{C}$. Much of this temperature dependence stems from an inverse temperature effect on uniform elongation in the unirradiated stainless steels.

(5) Calculations on strain-hardening rate during plastic instability predicted that the austenitic stainless steels would retain positive hardening capability during necking after irradiation to at least $9 \mathrm{dpa}$. This positive hardening capability was explained by the complexities of geometry and stress state in the necked region, which would activate additional dislocation slip systems or even different deformation mechanisms.

\section{Acknowledgments}

We would like to thank Dr. W. Sommer of LANL for arranging the collaborative irradiations on which this work is based and Drs R.L. Klueh and D.T. Hoelzer for technical review of the manuscript.

\section{References}

[1] L.K. Mansur, T.A. Gabriel, J.R. Haines and D.C. Lousteau, "R\&D for the Spallation Neutron Source Mercury Target", Fourth International Workshop on Spallation Materials, Schruns, Austria, Oct. 2000, J. of Nuclear Materials, 296 (2001) pp.1-16.

[2] K. Farrell and T.S. Byun, "Tensile Properties of Candidate SNS Target and Container Materials after Proton and Neutron Irradiation in the LANSCE Accelerator", Spallation Neutron Source Project Report: SNS/TSR-193, Oak Ridge National Laboratory, May, 2000.

[3] K. Farrell and T.S. Byun, "Tensile Properties of Candidate SNS Target Container Materials after Proton and Neutron Irradiation in the LANSCE Accelerator", Fourth International Workshop on Spallation Materials, Schruns, Austria, Oct. 2000, J. of Nuclear Materials, 296 (2001) pp.129-138.

[4] K. Farrell and T.S. Byun, "Tensile Properties of Candidate SNS Materials after Irradiation in Two Neutron Areas in LANSCE Accelerator", Spallation Neutron Source Project Report: SNS/TR-211, Oak Ridge National Laboratory, Jan, 2001.

[5] T.S. Byun, K. Farrell. E.H. Lee, J.D. Hunn and L.K. Mansur, "Strain Hardening and Plastic Instability Properties of Austenitic Stainless Steels after Proton and Neutron Irradiation”, J. of Nucl. Mater., 298 (2001) pp.269-279.

[6] S. A. Maloy, M. R. James, G. Wilcutt, W.F. Sommer, M. Sokolov, L. L. Snead, M. L. Hamilton, and F. Garner, "The Mechanical Properties of 316L/304L Stainless Steel, Alloy 718 and Mod 9Cr-1Mo after Irradiation in a Spallation Environment", Fourth International Workshop on Spallation Materials, Schruns, Austria, Oct. 2000, J. of Nuclear Materials, 296 (2001) pp.119128. 
[7] S. A. Maloy, "A Preliminary Report: The Change in the Mechanical Properties of Inconel 718, 304L, and 316 Stainless Steel and A16061 after Irradiation at the LANSCE Accelerator", TPO-RGN-0013, Los Alamos National Laboratory, Jan., 1999.

[8] J.E. Pawel, A.F. Rowcliffe, G.E. Lucas and S.J. Zinkle "Irradiation Performance of Stainless Steels for ITER Application”, J. Nucl. Mater., 239 (1996) pp.126-131.

[9] D.W. Kim, W.S. Ryu, J.H. Hong, S.K. Choi, "Effect of Nitrogen on the Dynamic Strain Ageing Behaviour of Type 316L Stainless Steel”, J. Mater. Sci., 33 (1998) pp.675-679.

[10] L. Shi and D.O. Northwood, "The Mechanical Behavior of an AISI Type 310 Stainless Steel”, Acta Metall. Mater., 43 (1995) pp.453-460.

[11] K. Farrell, "Participation of the ORNL-SNS Target Materials Group in the LANSCE-APT Materials Irradiation Experiment", SNS/TSR-0036, Oak Ridge National Laboratory, March 1998.

[12] W. F. Sommer, "Experience with Materials Performance at the LANSCE facility and an Irradiation Damage Effects Experiment Program", International Workshop on Spallation Materials Technology, Oak Ridge, April 23, 1996.

[13] S. A. Maloy, W. F. Sommer, R. D. Brown, J. E. Roberts, J. Eddleman, E. Zimmermann, and G. Willcutt, "Progress Report on the Accelerator Production of Tritium Materials Irradiation Program", Proceeding of the Symposium on Materials for Spallation Neutron Sources, Orlando, Florida, Feb. 9-13, 1997, The Minerals, Metals and Materials Society, Warrendale, Pa, 1998, pp. 131-138.

[14] M. S. Wechsler, M. H. Barnett, D.J. Dudjiak, L. K. Mansur, L. A. Charlton, J. M. Barnes, and J. O. Johnson, "Calculations of Radiation Effects on 316 Stainless Steel Container Materials for the NSNS", Proceedings of the Symposium on Materials for Spallation Neutron Sources, Orlando, Florida, Feb. 9-13, 1997, The Minerals, Metals and Materials Society, Warrendale, Pa, 1998, pp. 23-28.

[15] M.H. Barnett, M.S. Wechsler, D.J. Dudziak, L.K. Mansur and B.D. Murphy, "Radiation Damage to the 316 Stainless Steel Target Container Vessel at SNS, J. Nucl. Mater., 296 (2001) pp.54-60.

[16] M.L. Hamilton, "Reduction of Area Measurements on Selected APT Tensile Specimens", APT Project Technical Note: TPO-E20-Z-RTT-X-00002, Los Alamos National Laboratory, Jan., 2000.

[17] J. E. Pawel, A. F. Rowcliffe, G.E. Lucas, and S. J. Zinkle, "Irradiation Performance of Stainless Steels for ITER Application”, J. Nucl. Mater. 239 (1996) pp.126.

[18] J. D. Hunn, E. H. Lee, T. S. Byun, and L. K. Mansur, "Helium and Hydrogen Induced hardening in 316LN Stainless Steel”, J. of Nucl. Mater. 282 (2000) pp. 131-139. 
[19] Y. Dai, F. Carsughi, W.F. Sommer, G.S. Bauer and H. Ullmaier, "Tensile Properties and Microstructure of Martensitic Steel DIN 1.4926 after $800 \mathrm{MeV}$ Proton Irradiation”, J. Nucl.

Mater., 276 (2001) pp.289-294.

[20] Y. Dai, S.A. Maloy, G.S. Bauer and W.F. Sommer, "Mechanical Properties and Microstructure in Low-Activation Martensitic Steels F82H and Optimax after 800-MeV Proton Irradiation”, J. Nucl. Mater., 276 (2000) pp.513-517.

[21] K. Shiba, R.L. Klueh, Y. Miwa, J.P. Robertson, A. Hishinuma, “Tensile Behavior of F82H with and without Spectral Tailoring”, J. Nucl. Mater., 283-287 (2000) pp.358-361.

[22] G. E. Dieter, “ Mechanical Metallurgy”, 3rd Ed. McGraw-Hill (1986) pp.283-292.

[23] K. Farrell, T. S. Byun, and N. Hashimoto, Unpublished results on Tensile Properties and Deformation Microstructures of $316 \mathrm{LN}$ and $304 \mathrm{~L}$ Stainless Steels at -150 to $200^{\circ} \mathrm{C}$.

[24] E. V. van Osch and M.I. de Vries, "Irradiation Hardening of V-4Cr-4Ti”, J. Nucl. Mat., 271\&272 (1999) pp.161-166.

[25] J. Aronofsky, "Evaluation of Stress Distribution in the Symmetrical Neck of Flat Tensile Bars", J. Appl. Mech., 18 (1951) pp.75-84.

[26] T.S. Byun, E.H. Lee, J.D. Hunn, K. Farrell and L.K. Mansur, "Characterization of Plastic Deformation in a Disk Bend Test”, J. Nucl. Mater., 294 (2001) pp.256-266. 
Table 1. Compositions of test materials

\begin{tabular}{|c|c|c|c|c|c|c|c|c|c|c|c|c|}
\hline \multirow[t]{2}{*}{ Material } & \multirow{2}{*}{$\begin{array}{l}\text { I D } \\
\text { Mark }\end{array}$} & \multicolumn{11}{|c|}{ Composition ( Wt. \%) } \\
\hline & & Bal. & $\mathrm{Ni}$ & $\mathrm{Cr}$ & Mo & $\mathrm{Mn}$ & Si & C & $\mathrm{N}$ & $\mathrm{Nb}$ & V & Other \\
\hline EC $316 \mathrm{LN}^{1}$ & $E$ & $\mathrm{Fe}$ & 12.2 & 17.45 & 2.5 & 1.81 & .39 & .024 & .067 & & & \\
\hline $\begin{array}{l}\text { 9Cr-2WVTa } \\
\text { steel (Ht. } \\
3791)^{2}\end{array}$ & Q & $\mathrm{Fe}$ & $<.01$ & 8.90 & .01 & .44 & .21 & .11 & .021 & $<.01$ & .23 & $\begin{array}{l}2.01 \mathrm{~W} ; \\
.06 \mathrm{Ta}\end{array}$ \\
\hline
\end{tabular}

${ }^{1}$ Annealed $1 \mathrm{~h} @ 950^{\circ} \mathrm{C}$ in vacuum

${ }^{2}$ Wrapped in $\mathrm{Zr}$ foil and annealed 30 min.@ $1050^{\circ} \mathrm{C}$ in helium, fast cool; reheated $1 \mathrm{~h} @ 750^{\circ} \mathrm{C}$, fast cool 
Table 2. Irradiation conditions for SS-3 tensile specimens

\begin{tabular}{|c|c|c|c|c|c|c|c|c|c|c|c|c|c|}
\hline \multirow[t]{2}{*}{$\begin{array}{c}\text { ID } \\
\text { Mark }\end{array}$} & \multirow[t]{2}{*}{ Material } & \multirow{2}{*}{$\begin{array}{l}\text { Insert- } \\
\text { Tube- } \\
\text { Sandwich }\end{array}$} & \multirow{2}{*}{$\begin{array}{c}\text { Distance* } \\
(\mathrm{mm})\end{array}$} & \multirow{2}{*}{$\begin{array}{c}\text { Height* }^{*} \\
(\mathrm{~mm})\end{array}$} & \multirow{2}{*}{$\begin{array}{c}\text { Irr. } \\
\text { Temp. } \\
\left({ }^{\circ} \mathrm{C}\right)\end{array}$} & \multirow[t]{2}{*}{ dpa } & \multirow[t]{2}{*}{$\begin{array}{c}\mathrm{He} \\
(\mathrm{appm})\end{array}$} & \multirow[t]{2}{*}{$\begin{array}{c}\mathrm{H} \\
(\text { appm })\end{array}$} & \multirow{2}{*}{$\begin{array}{c}\text { Proton } \\
\text { fluence } \\
\left(10^{24}\right. \\
\left.\mathrm{p} / \mathrm{m}^{2}\right)\end{array}$} & \multicolumn{4}{|c|}{ Neutron fluence $\left(10^{24} \mathrm{n} / \mathrm{m}^{2}\right)$} \\
\hline & & & & & & & & & & $\begin{array}{c}\mathrm{E}<0.1 \\
\mathrm{MeV}\end{array}$ & {$\left[\begin{array}{c}0.1 \mathrm{MeV} \\
<\mathrm{E}< \\
20 \mathrm{MeV}\end{array}\right.$} & $\begin{array}{c}20 \mathrm{MeV} \\
<\mathrm{E}< \\
150 \mathrm{MeV}\end{array}$ & $\begin{array}{c}E>150 \\
M e V\end{array}$ \\
\hline E50 & EC316LN & 17A-4-6 & 15.2 & 3.0 & 94 & 1.87 & 133.1 & 1110.8 & 5.68 & 0.16 & 1.49 & 0.45 & 0.25 \\
\hline E51 & EC316LN & $17 A-4-6$ & 40.6 & 3.0 & 39 & 0.54 & 34.2 & 274.3 & 1.17 & 0.16 & 0.80 & 0.14 & 0.08 \\
\hline E54 & EC316LN & $17 A-4-6$ & 40.6 & 3.0 & 39 & 0.54 & 34.2 & 274.3 & 1.17 & 0.16 & 0.80 & 0.14 & 0.08 \\
\hline E55 & EC316LN & $17 A-4-6$ & 15.2 & 3.0 & 94 & 1.87 & 133.1 & 1110.8 & 5.68 & 0.16 & 1.49 & 0.45 & 0.25 \\
\hline Q19 & 9Cr-2WVTa & 17A-4-6 & -10.2 & 3.0 & 100 & 2.53 & 181.8 & 1522.2 & 8.04 & 0.21 & 1.57 & 0.68 & 0.24 \\
\hline Q20 & 9Cr-2WVTa & $17 A-4-6$ & -35.6 & 3.0 & 46 & 0.64 & 41.5 & 350.9 & 1.28 & 0.16 & 1.02 & 0.18 & 0.08 \\
\hline Q21 & 9Cr-2WVTa & $17 A-4-6$ & -10.2 & 3.0 & 100 & 2.53 & 181.8 & 1522.2 & 8.04 & 0.21 & 1.57 & 0.68 & 0.24 \\
\hline Q22 & 9Cr-2WVTa & 17A-4-6 & -35.6 & 3.0 & 46 & 0.64 & 41.5 & 350.9 & 1.28 & 0.16 & 1.02 & 0.18 & 0.08 \\
\hline
\end{tabular}

* positions of specimen centers from beam center; in the perpendicular directions to the beam direction 
Table 3. Tensile properties of irradiated and unirradiated steels

\begin{tabular}{|l|c|c|c|c|c|c|c|c|}
\hline Materials & ID Mark & dpa & $\begin{array}{c}\text { Irr. Temp. } \\
\left({ }^{\circ} \mathrm{C}\right)\end{array}$ & $\begin{array}{c}\text { Test Temp. } \\
\left({ }^{\circ} \mathrm{C}\right)\end{array}$ & YS (MPa) & UTS (MPa) & UE (\%) & TE (\%) \\
\hline EC316LN & E19 & 0 & - & 20 & 279 & 645 & 68.6 & 78.0 \\
\hline & E51 & 0.54 & 39 & 20 & 636 & 769 & 30.0 & 39.5 \\
\hline & E50 & 1.87 & 94 & 20 & 837 & 865 & 15.7 & 23.7 \\
\hline & E12 & 0 & - & 164 & 239 & 532 & 50.6 & 59.0 \\
\hline & E54 & 0.54 & 39 & 164 & 550 & 658 & 24.9 & 31.6 \\
\hline & E55 & 1.87 & 94 & 164 & 740 & 750 & 14.5 & 20.9 \\
\hline 9Cr-2VWTa & Q16 & 0 & - & 20 & 536 & 700 & 8.6 & 16.3 \\
\hline & Q20 & 0.64 & 46 & 20 & 881 & $*$ & 0.1 & 7.2 \\
\hline & Q19 & 2.53 & 100 & 20 & 978 & $*$ & 0.2 & 4.6 \\
\hline & Q17 & 0 & - & 164 & 526 & 641 & 6.9 & 14.7 \\
\hline & Q22 & 0.64 & 46 & 164 & 803 & $*$ & 0.3 & 7.0 \\
\hline & Q21 & 2.53 & 100 & 164 & 880 & $*$ & 0.1 & 4.0 \\
\hline
\end{tabular}

${ }^{*} \mathrm{UTS}=\mathrm{YS}$ 
Table 4. True strain to plastic instability in $316 \mathrm{~L}$ and EC316LN stainless steels

\begin{tabular}{|c|c|c|c|c|}
\hline ID & Material (Origin) & dpa & Test Temp. $\left({ }^{\circ} \mathrm{C}\right)$ & $\begin{array}{c}\text { True Strain to } \\
\text { Plastic Instability }\end{array}$ \\
\hline E15 & EC316LN (ORNL) & 0 & 20 & 0.434 \\
\hline $316-1$ & 316L(LANL) & 0 & 20 & 0.438 \\
\hline E12 & EC316LN (ORNL) & 0 & 20 & 0.494 \\
\hline E7 & EC316LN (ORNL) & 0.45 & 20 & 0.292 \\
\hline E51 & EC316LN (ORNL) & 0.54 & 20 & 0.248 \\
\hline E8 & EC316LN (ORNL) & 0.65 & 20 & 0.287 \\
\hline E1 & EC316LN (ORNL) & 0.86 & 20 & 0.296 \\
\hline E4 & EC316LN (ORNL) & 1.11 & 20 & 0.237 \\
\hline E9 & EC316LN (ORNL) & 1.36 & 20 & 0.290 \\
\hline E55 & EC316LN (ORNL) & 1.87 & 20 & 0.129 \\
\hline E2 & EC316LN (ORNL) & 2.43 & 20 & 0.180 \\
\hline E5 & EC316LN (ORNL) & 2.53 & 20 & 0.231 \\
\hline E6 & EC316LN (ORNL) & 3.64 & 20 & 0.211 \\
\hline E3 & EC316LN (ORNL) & 10.67 & 20 & 0.088 \\
\hline $316-5$ & 316L(LANL) & 0 & 50 & 0.383 \\
\hline 1A1a & 316L(LANL) & 0.09 & 50 & 0.190 \\
\hline $24-6-9$ & 316L(LANL) & 1 & 50 & 0.232 \\
\hline $24-5-1$ & 316L(LANL) & 1.2 & 50 & 0.179 \\
\hline $24-6-8$ & 316L(LANL) & 2.9 & 50 & 0.199 \\
\hline $4-6-5$ & 316L(LANL) & 8.8 & 50 & 0.007 \\
\hline $316-7$ & 316L(LANL) & 0 & 164 & 0.297 \\
\hline E19 & EC316LN (ORNL) & 0 & 164 & 0.387 \\
\hline E54 & EC316LN (ORNL) & 0.54 & 164 & 0.204 \\
\hline E50 & EC316LN (ORNL) & 1.87 & 164 & 0.116 \\
\hline $4-6-9$ & 316L(LANL) & 2.9 & 164 & 0.018 \\
\hline $24-6-6$ & 316L(LANL) & 4.1 & 164 & 0.033 \\
\hline $4-6-7$ & 316L(LANL) & 8.7 & 164 & 0.003 \\
\hline $4-6-6$ & 316L(LANL) & 9.2 & 164 & 0.002 \\
\hline
\end{tabular}


Table 5. Strain-hardening rate on plastic instability in irradiated 316L stainless steel

\begin{tabular}{|l|c|c|c|c|c|c|c|c|}
\hline ID Mark & dpa & dpa & RA $(\%)$ & $\varepsilon_{f}$ & $\varepsilon_{u}$ & $\sigma_{u}(\mathrm{MPa})$ & $S_{f}(\mathrm{MPa})$ & $h_{n}(\mathrm{MPa})$ \\
\hline $24-5-1^{\mathrm{a}}$ & 1.2 & 1.2 & 72.9 & 1.32 & 0.182 & 933 & 580 & 1090 \\
\hline $24-6-6^{\mathrm{b}}$ & 4.1 & 4.1 & 82.7 & 1.75 & 0.004 & 705 & 291 & 560 \\
\hline $4-6-6^{\mathrm{b}}$ & 9.2 & 9.2 & 63.6 & 1.00 & 0.002 & 859 & 613 & 800 \\
\hline
\end{tabular}

${ }^{\mathrm{a}}$ Tested at $50{ }^{\circ} \mathrm{C}$

${ }^{b}$ Tested at $164{ }^{\circ} \mathrm{C}$ 


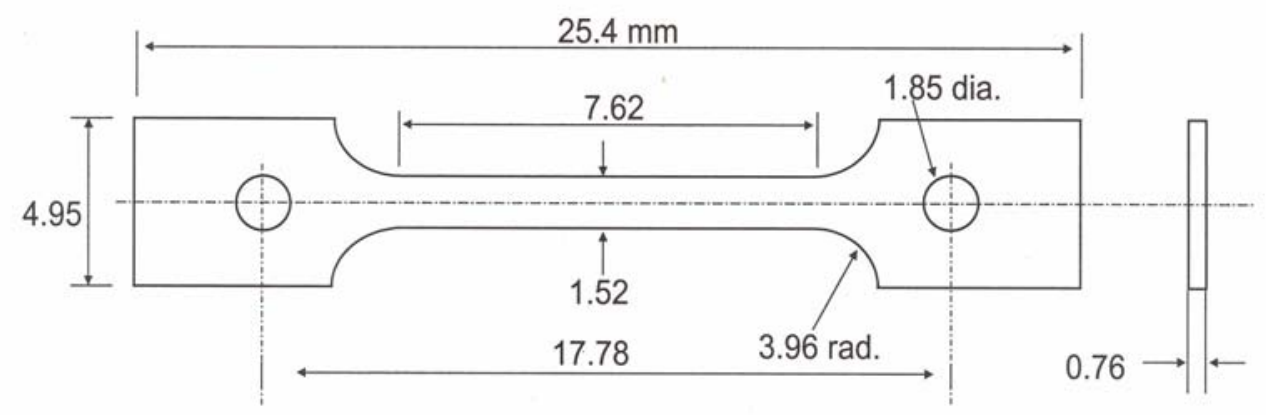

SS-3 Tensile Specimen

Fig. 1. Dimensions of SS-3 tensile specimen. 


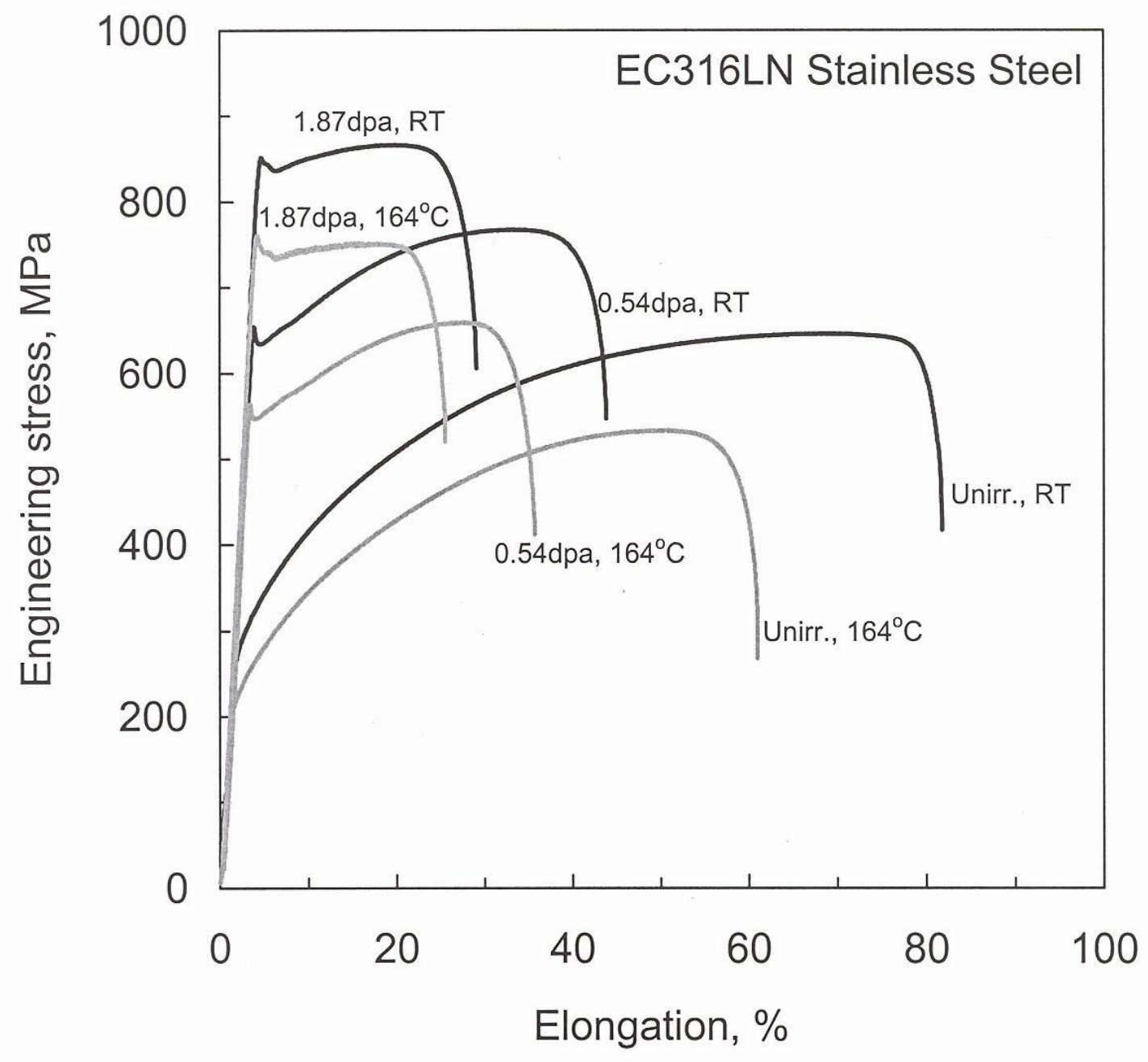

Fig. 2. Engineering stress-strain curves of EC316LN stainless steel after irradiation to labeled doses in spallation environments. 


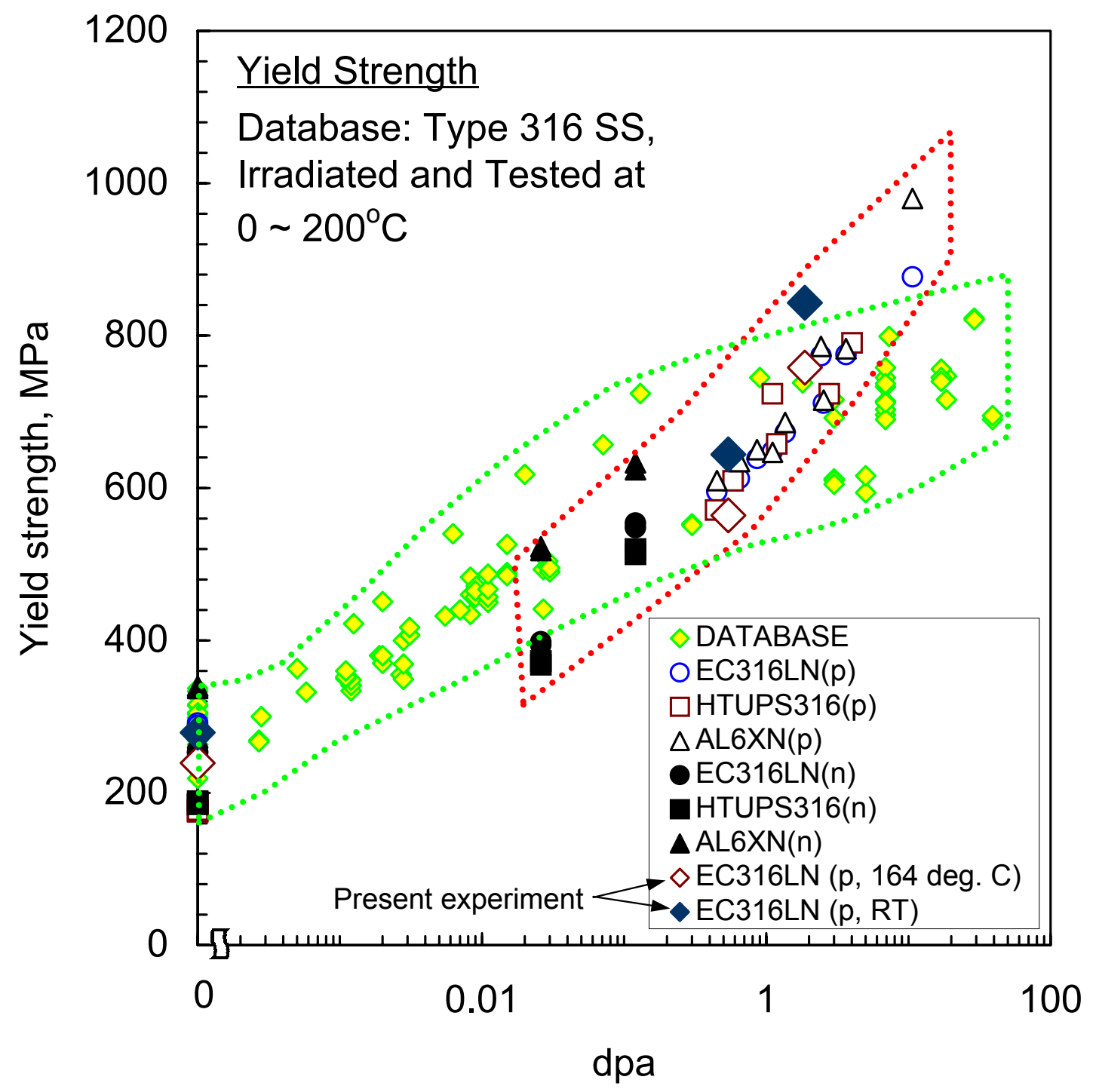

Fig. 3. Yield stresses of EC $316 \mathrm{LN}$ stainless steel compared with database for 316 stainless steels irradiated in fission reactors and with room temperature data for austenitic stainless steels irradiated in spallation conditions ( $\mathrm{p}$ and $\mathrm{n}$ denote proton and neutron dominant areas, respectively). 


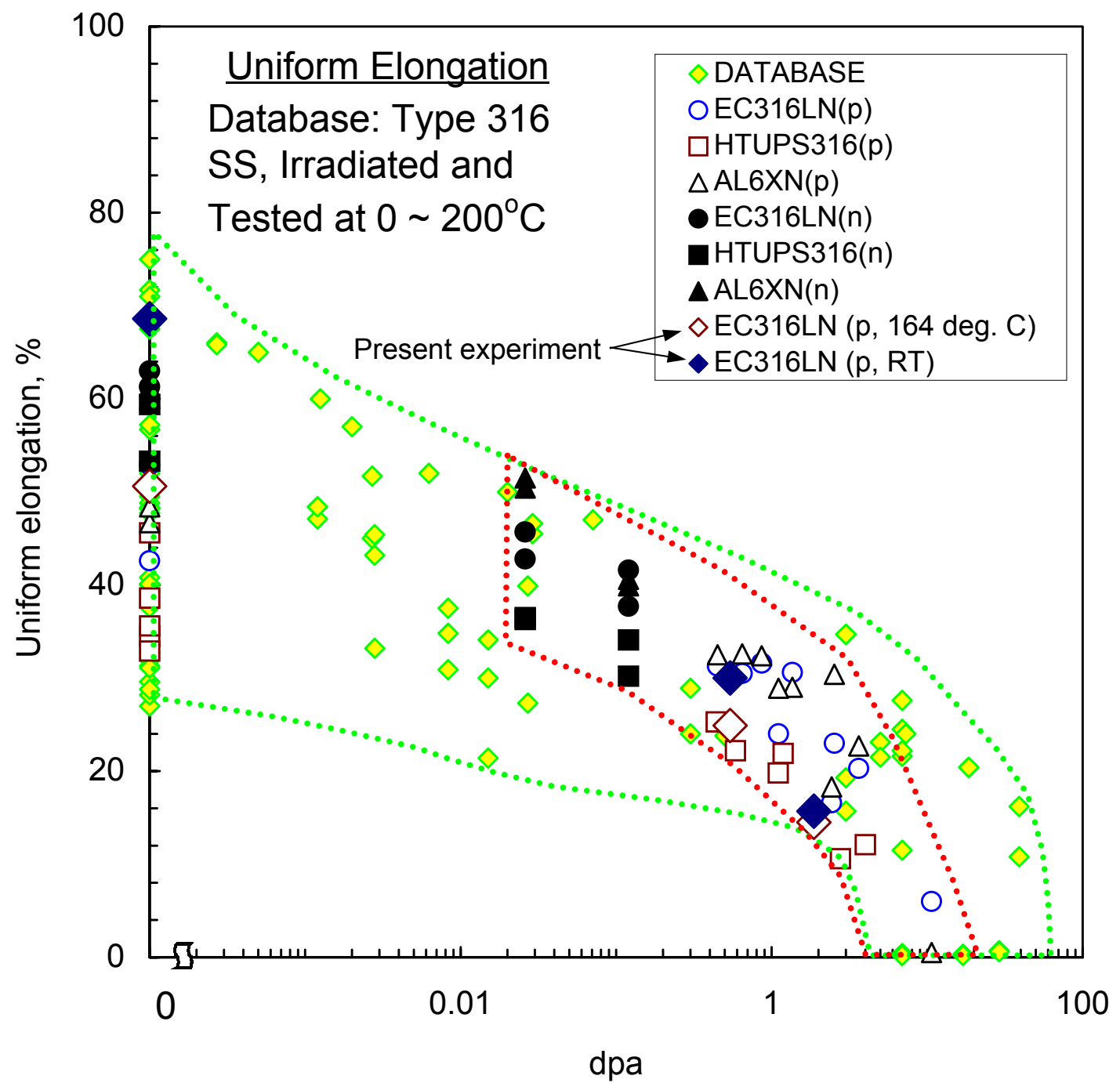

Fig. 4. Uniform elongations of EC316LN stainless steel compared with database for 316 stainless steels irradiated in fission reactors and with room temperature data for austenitic stainless steels irradiated in spallation conditions ( $\mathrm{p}$ and $\mathrm{n}$ denote proton and neutron dominant areas, respectively). 


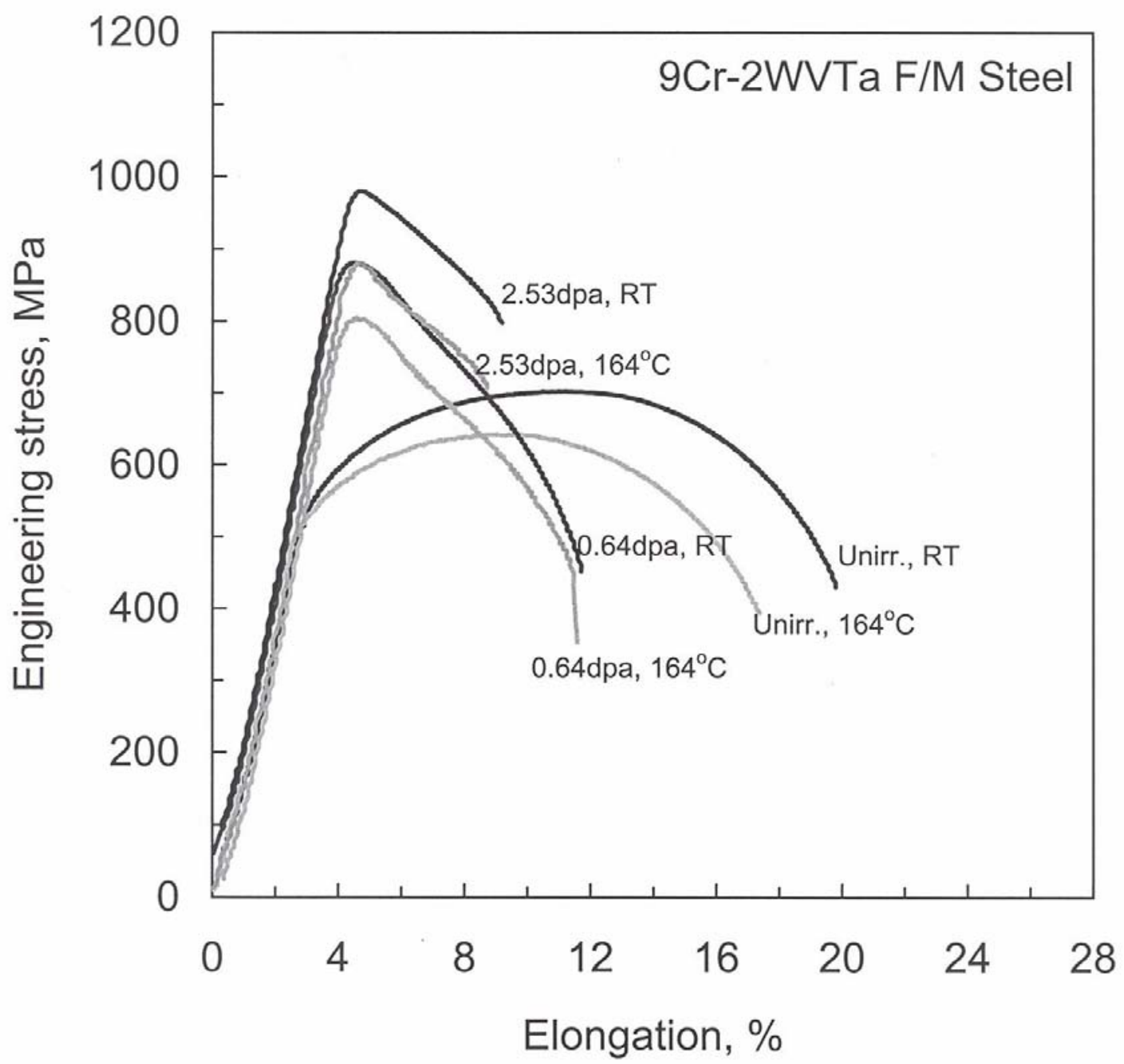

Fig. 5. Engineering stress-strain curves of 9Cr-2WVTa ferritic/martensitic steel after irradiation to labeled doses in spallation environments. 


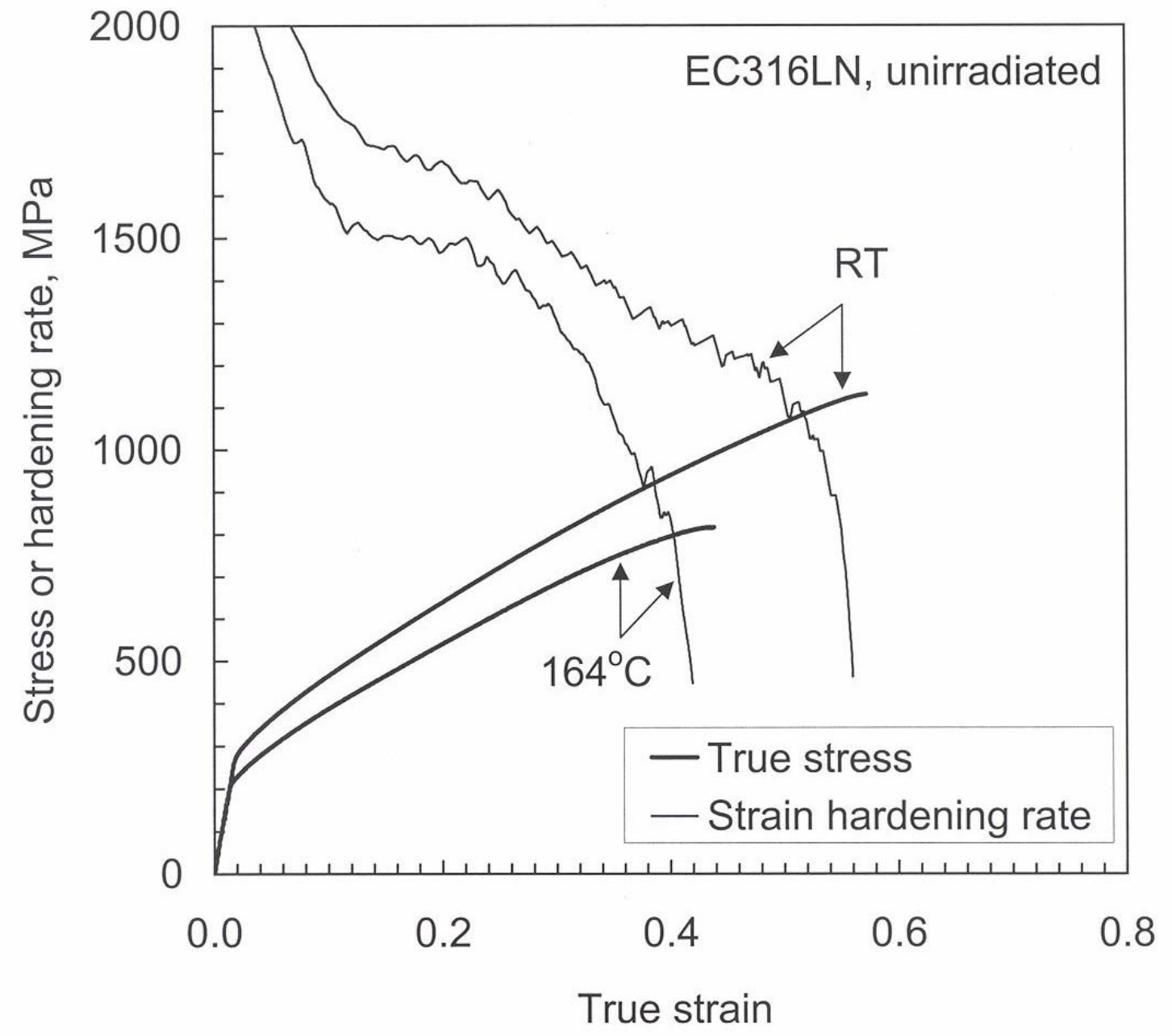

Fig. 6. True stress vs. true strain and strain-hardening rate vs. true strain curves of EC316LN stainless steel before irradiation. 


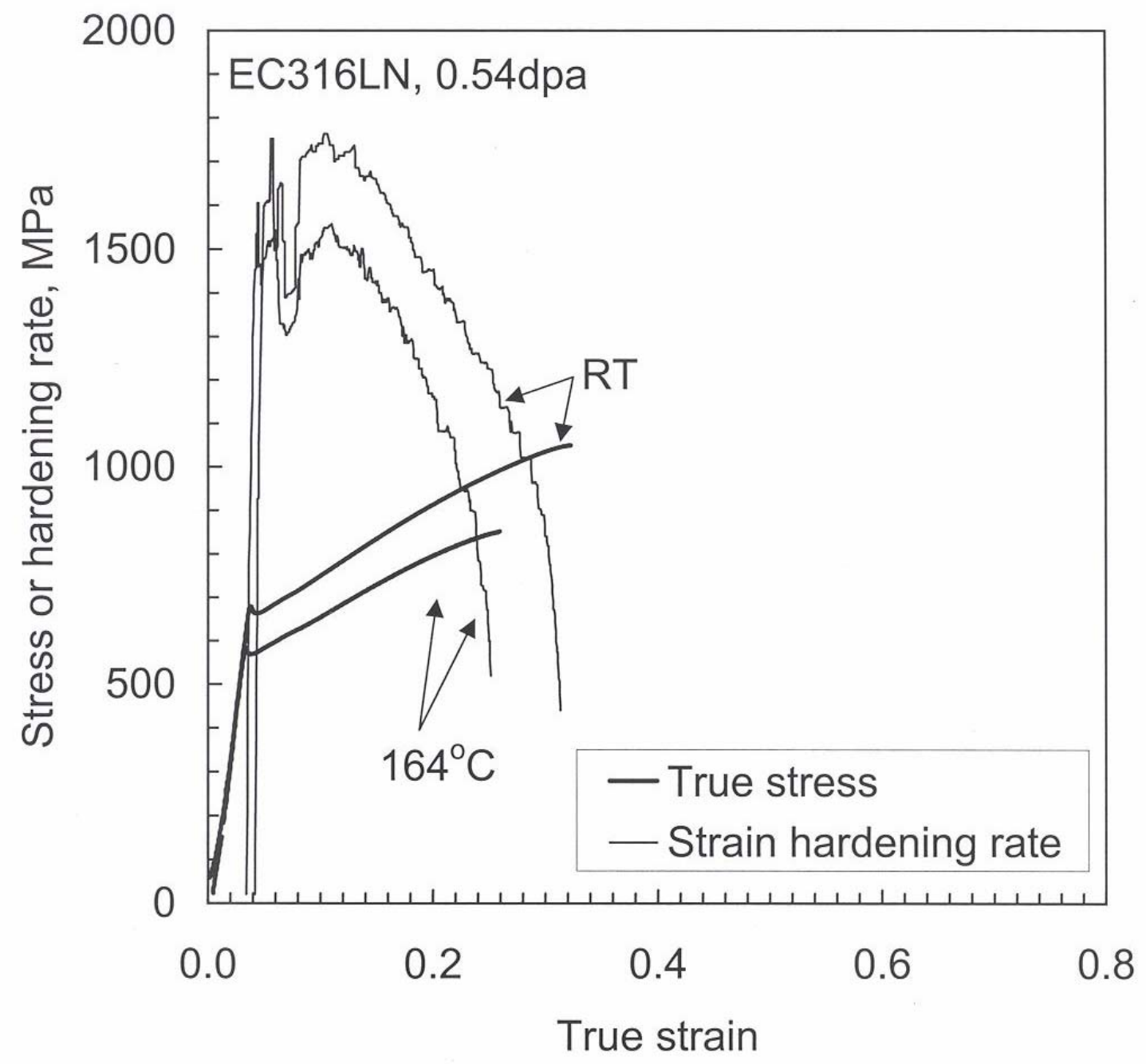

Fig. 7. True stress vs. true strain and strain-hardening rate vs. true strain curves of EC316LN stainless steel after irradiation to $0.54 \mathrm{dpa}$. 


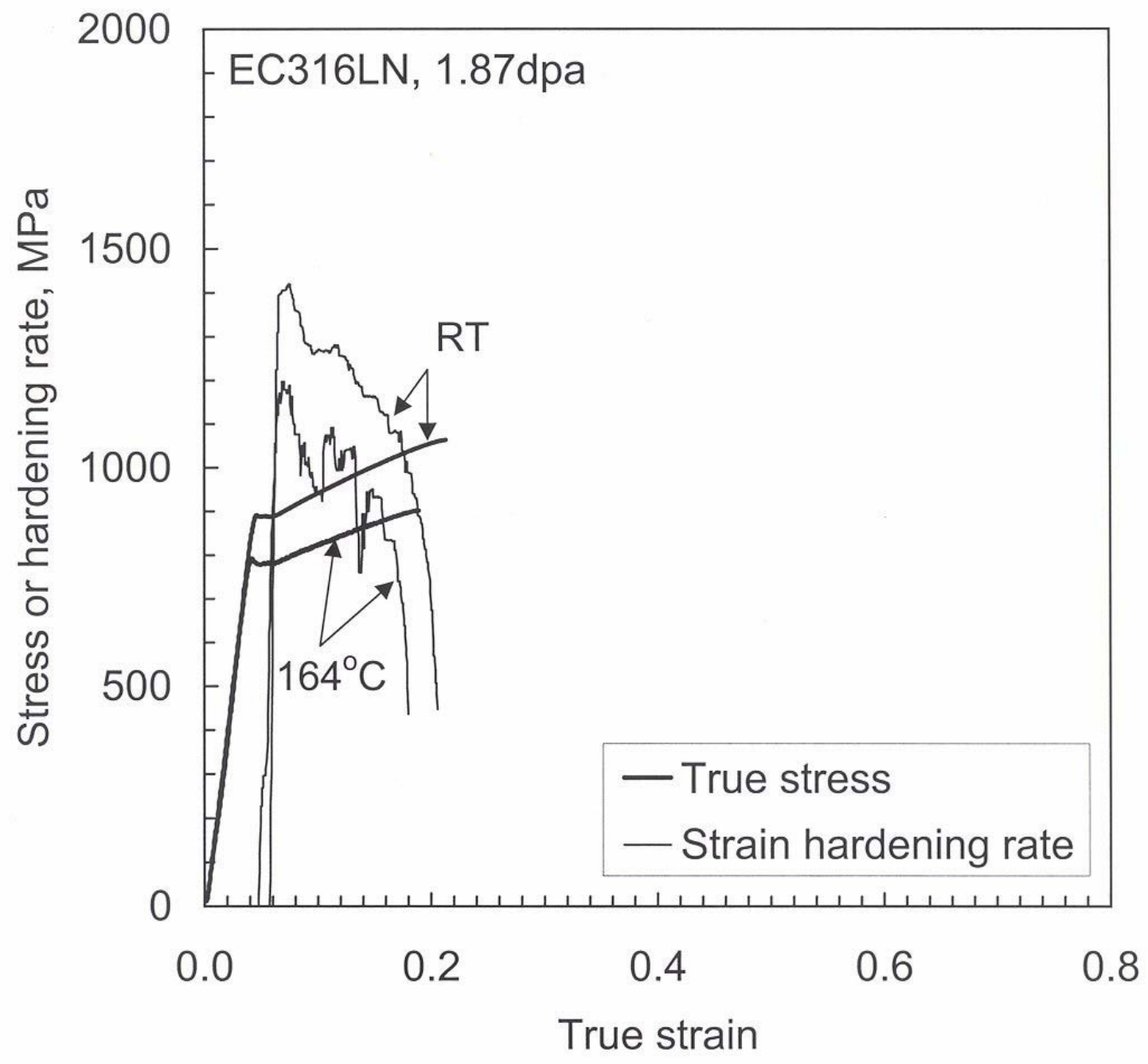

Fig. 8. True stress vs. true strain and strain-hardening rate vs. true strain curves of EC316LN stainless steel after irradiation to $1.87 \mathrm{dpa}$. 


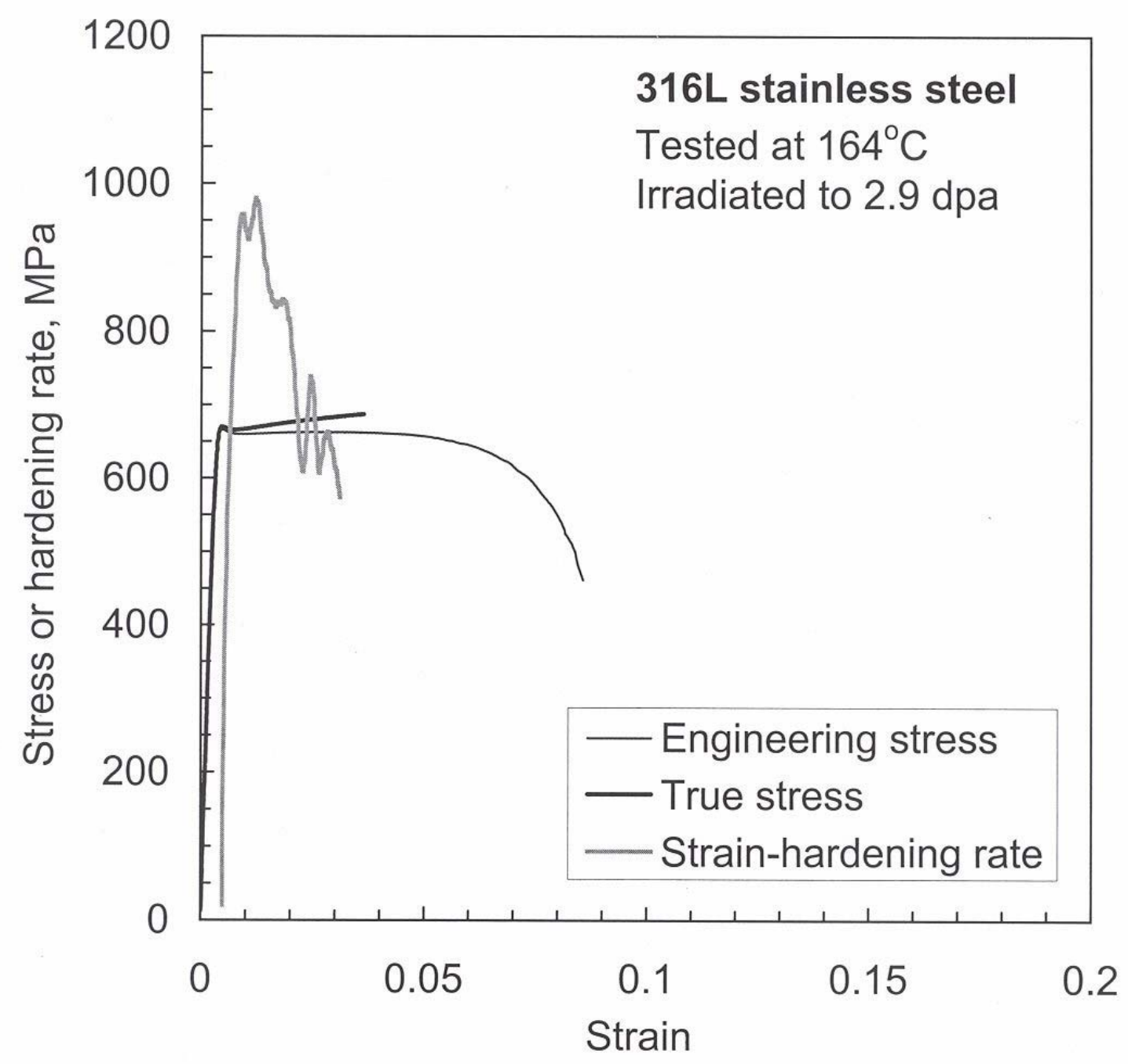

Fig. 9. Comparison of engineering stress-strain, true stress-true strain and strainhardening rate vs. true strain curves of $316 \mathrm{~L}$ stainless steel at $164^{\circ} \mathrm{C}$ after irradiation to 2.9 dpa. 


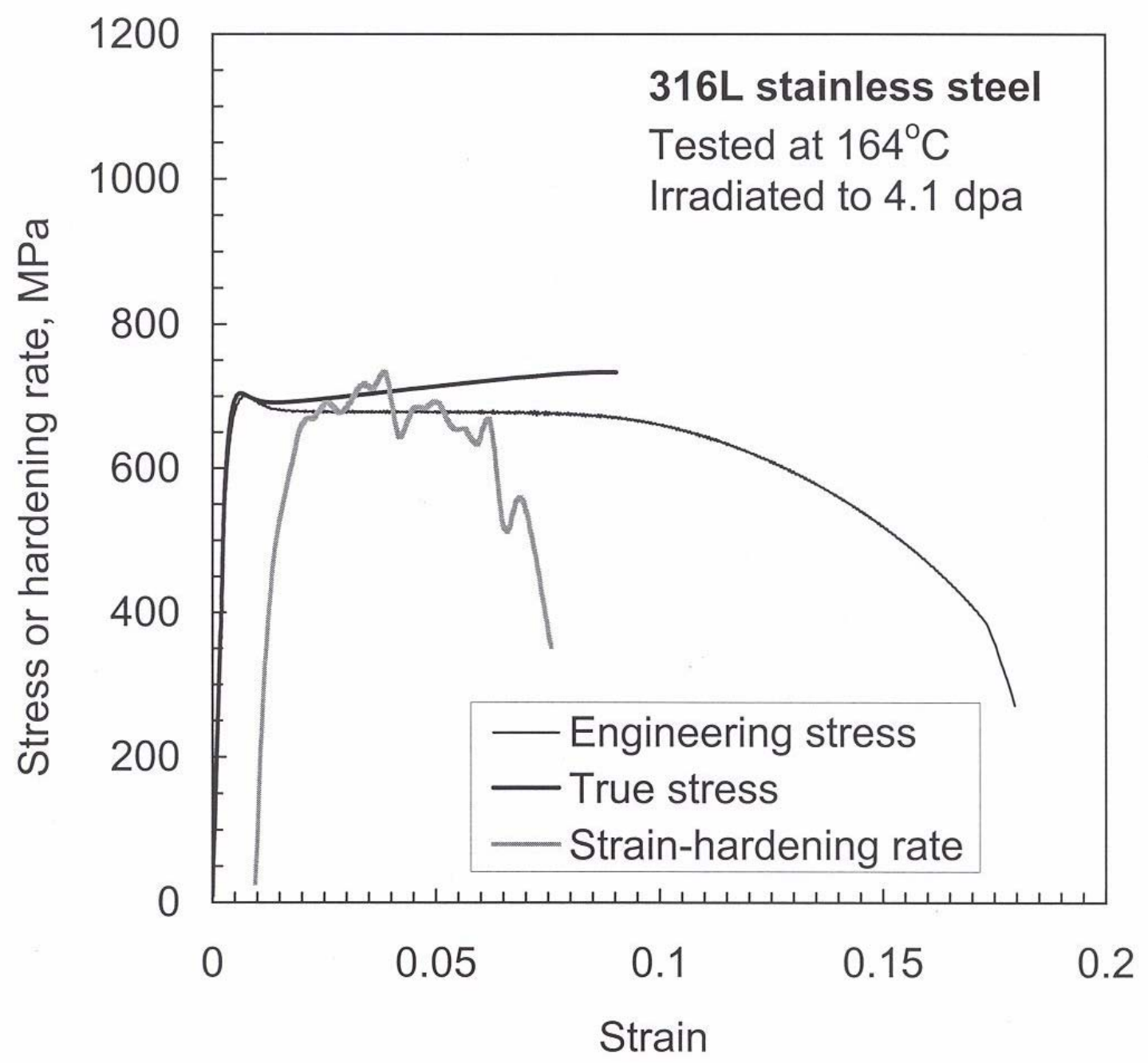

Fig. 10. Comparison of engineering stress-strain, true stress-true strain and strainhardening rate vs. true strain curves of $316 \mathrm{~L}$ stainless steel at $164^{\circ} \mathrm{C}$ after irradiation to 4.1 dpa. 


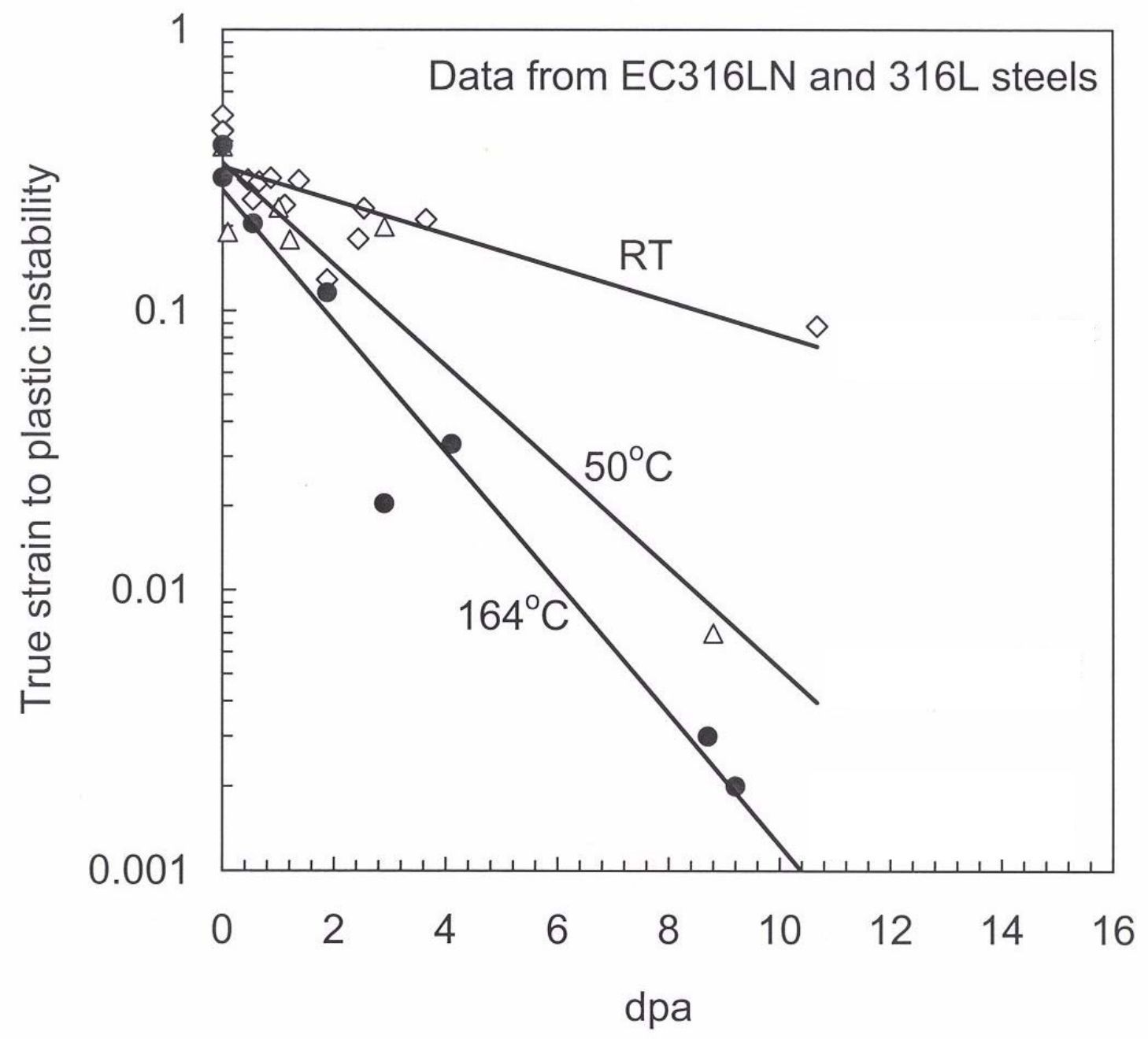

Fig. 11. Dose dependence of true strain to plastic instability. 
SNS-101060100-TR0003-R00

\section{Distribution}

1. E. E. Bloom

2. T. S. Byun

3. K. Farrell

4. T. A. Gabriel

5. J. R. Haines

6. J. D. Hunn

7. L. L. Horton

8. R.D. Lawson

9. D. C. Lousteau

10. L. K. Mansur

11. T. J. McManamy

12. B. W. Riemer

13. S. J. Pawel

14. S. J. Zinkle

15. ORNL Central Research Library

16. ORNL Laboratory Records

17. M. R. James, Los Alamos National Laboratory, MS H809, Los Alamos, NM 87549

18. S. A. Maloy, Los Alamos National Laboratory, MS H809, Los Alamos, NM 87549

19. W. R. Johnson, General Atomics, P.O. Box 85608, San Diego, CA 92186 